\title{
Híbridos e variedades de milho submetidos à inoculação de sementes com Herbaspirillum seropedicae
}

\section{Hybrids and varieties of corn inoculated with Herbaspirillum seropedicae}

\author{
Fabio Fernando de Araujo ${ }^{*}$; José Salvador Simoneti Foloni²; \\ Marlon Wutzke ${ }^{3}$; Alexandre da Silva Melegari³; Eder Rack ${ }^{3}$
}

\section{Resumo}

\begin{abstract}
A fixação biológica de nitrogênio proporcionada por bactérias diazotróficas pode representar alternativa para a produção de milho em sistemas agrícolas mais sustentáveis ou de baixa utilização de insumos. Objetivando-se avaliar o crescimento, teor e acúmulo de nitrogênio em genótipos de milho, em função da inoculação das sementes com Herbaspirillum seropedicae, foi conduzido experimento em casa de vegetação avaliando-se 35 genótipos de milho híbridos simples, duplo, triplo e variedades. Para inoculação das sementes foi utilizado inoculante turfoso contendo a estirpe bacteriana de $H$. seropedicae (ZAE 94). Entre os genótipos comerciais de milho estudados, apenas nove híbridos apresentam ganhos de crescimento ou acúmulo de $\mathrm{N}$ com a inoculação das sementes com a estirpe Herbaspirillum seropedicae (ZAE 94). Há distinção de resposta entre cultivares de milho em termos de produção de biomassa e incremento de teor de $\mathrm{N}$ na parte aérea das plantas.
\end{abstract}

Palavras-chave: Zea mays, bactérias diazotróficas, fixação biológica de nitrogênio

\begin{abstract}
The biological nitrogen fixation provided by diazotrophic bacteria may represent an alternative to maize production in more sustainable agricultural systems or low use of technology. In order to evaluate the growth, content and accumulation of nitrogen in corn genotypes, depending on seed inoculation with Herbaspirillum seropedicae experiment was conducted in greenhouse evaluating 35 corn genotypes hybrid single, double, triple and varieties. For seed inoculation was used peat inoculant containing the bacterial strain of $H$. seropedicae (ZAE 94). Among the commercial corn genotypes studied, only nine hybrids show increase of growth or accumulation of $\mathrm{N}$ with the seed inoculation with Herbaspirillum seropedicae (ZAE 94). There is a distinction in response between maize cultivars in terms of biomass production and increase of $\mathrm{N}$ content in the shoots.
\end{abstract}

Key words: Zea mays, diazotrophic bacteria, nitrogen fixation

1 Eng ${ }^{\circ}$ Agr ${ }^{\circ}$, Prof. Dr. da Faculdade de Ciências Agrárias, Universidade do Oeste Paulista, UNOESTE, Presidente Prudente, SP. E-mail: fabio@unoeste.br

2 Eng ${ }^{\circ}$ Agr ${ }^{\circ}$, Pesquisador, Dr. da Área de Manejo do Solo e da Cultura, Embrapa Soja, Londrina, PR. E-mail: salvador.foloni@ embrapa.br

3 Eng ${ }^{\circ \mathrm{s}}$ Agr $^{{ }^{\circ} \text {, }}$, Faculdade de Ciências Agrárias, UNOESTE, Presidente Prudente, SP. E-mail: mwutzke@hotmail.com.br; melegari@ gmail.com; eder_rack@hotmail.com.br

* Autor para correspondência 


\section{Introdução}

Nas últimas décadas várias espécies de bactérias diazotróficas endofíticas têm sido isoladas de gramíneas, dentre elas pode-se destacar: Azospirillum lipoferum, Azospirillum brasiliense e Herbaspirilumm seropedicae (RIGGS et al., 2001). Em condições de campo, a utilização de inoculantes com estirpes de Azospirillum brasiliense aumentou a fitomassa seca da parte aérea e o rendimento de grãos de milho, em cultivos na Argentina e no Brasil (REIS et al., 2000).

Os fertilizantes nitrogenados representam mais de $70 \%$ do custo de adubação do milho, o que influencia expressivamente a viabilidade econômica da cultura (MACHADO et al., 1998). Cultivares adaptados a ambientes pobres em nitrogênio $(\mathrm{N})$ e capazes de se associar a bactérias diazotróficas, podem representar alternativa economicamente viável para a produção de milho em sistemas agrícolas com baixo aporte de insumos. Entretanto, o melhoramento genético no milho é geralmente conduzido com a aplicação de quantidades elevadas de N mineral (ROESCH et al., 2005).

O uso de doses relativamente altas de $\mathrm{N}$ durante o crescimento de cultivares híbridos de milho pode levar à seleção de genótipos que apresentem consumo de luxo do nutriente e/ou que requeiram elevada adubação nitrogenada para expressar seu potencial produtivo (CARLONE; RUSSEL, 1987). Por outro lado, baixas doses de $\mathrm{N}$ podem contribuir naturalmente para a seleção de genótipos eficientes na associação com bactérias fixadoras de $\mathrm{N}$ (FBN), os quais podem contribuir para a redução no consumo de fertilizantes industrializados (BODDEY et al., 1995; ROESCH et al., 2005).

De acordo com Sawazaki e Paterniani (2004), os principais genótipos de milho comerciais disponíveis no Brasil podem ser classificados e caracterizados resumidamente da seguinte forma: (1) variedades, caracterizadas por populações de base genética ampla, podendo ser cultivadas por agricultores por sucessivos anos; (2) híbridos simples que são resultantes do cruzamento de duas linhagens endogâmicas divergentes, caracterizandose pelo elevado grau de uniformidade e alto potencial produtivo; (3) híbridos duplos resultantes do cruzamento de dois híbridos simples, apresentando maior variabilidade genética entre os híbridos de milho, sendo, portanto, menos sujeitos a adversidades ambientais, além de terem menor uniformidade fenotípica; (4) híbridos triplos, os quais são obtidos do cruzamento entre um híbrido simples, utilizado como progenitor feminino, com uma terceira linhagem endogâmica masculina; (5) híbridos "top cross", resultantes dos cruzamentos entre híbridos e variedades, ou entre variedades e linhagens.

Avaliando a contribuição da FBN em nove genótipos milho, incluindo híbridos e variedades, Mendonça, Urquiaga e Reis (2006) relataram que todos os genótipos não receberam significativa contribuição da FBN. As razões que levam à variação de resposta de FBN em gramíneas ainda não foram completamente elucidadas, sugerindo que a interação entre genótipo e ambiente tenha expressiva influência sobre a eficiência de organismos diazotróficos (GYANESHWAR et al., 2002).

Com a hipótese de que a amplitude genética possa influenciar a interação do milho com bactérias diazotróficas endofíticas, objetivou-se avaliar o crescimento inicial e o acúmulo de $\mathrm{N}$ em 35 genótipos de milho (híbridos simples, triplos, duplos e variedades), na ausência e presença de inoculação das sementes com Herbaspirillum seropedicae.

\section{Material e Métodos}

O experimento foi conduzido em casa de vegetação, durante março a junho de 2009. Utilizouse uma porção de solo agrícola coletada na camada arável (0-20 cm de profundidade), cuja classificação foi de um Argissolo Vermelho distroférrico de textura média (EMBRAPA, 2006), localizado num relevo suave ondulado, com horizontes bem 
desenvolvidos e boa drenagem. A porção de solo foi secada ao ar e passada em peneira com malha de $2 \mathrm{~mm}$. Em seguida, foram retiradas amostras para caracterização de atributos químicos (RAIJ et al., 2001) e granulometria (EMBRAPA, 1997), encontrando-se os seguintes valores: $\mathrm{pH}\left(\mathrm{CaCl}_{2} 1\right.$ $\left.\mathrm{mol} \mathrm{L}^{-1}\right)$ de 5,3; $13 \mathrm{~g} \mathrm{dm}^{-3}$ de $\mathrm{MO} ; 8 \mathrm{mg} \mathrm{dm}^{-3} \mathrm{de}_{\text {resina }}$; $19 \mathrm{mmol}_{\mathrm{c}} \mathrm{dm}^{-3} \mathrm{de} \mathrm{H}+\mathrm{Al} ; 1,5 \mathrm{mmol}_{\mathrm{c}} \mathrm{dm}^{-3}$ de $\mathrm{K} ; 18$ $\mathrm{mmol}_{\mathrm{c}} \mathrm{dm}^{-3} \mathrm{de} \mathrm{Ca} ; 14 \mathrm{mmol}_{\mathrm{c}} \mathrm{dm}^{-3} \mathrm{de} \mathrm{Mg} ; 52 \mathrm{mmol}_{\mathrm{c}}$ $\mathrm{dm}^{-3}$ de CTC; 64\% de saturação por bases (V); $730 \mathrm{~g}$ $\mathrm{kg}^{-1}$ de areia; $80 \mathrm{~g} \mathrm{~kg}^{-1}$ de silte; $190 \mathrm{~g} \mathrm{~kg}^{-1}$ de argila.

A capacidade de campo de amostras do solo desestruturado (peneirado) foi determinada no aparelho extrator de Richards a $-0,03 \mathrm{MPa}$ (EMBRAPA, 1997), e o valor encontrado foi de 175 $\mathrm{g} \mathrm{kg}^{-1}$, para quatro repetições. Aplicou-se calcário dolomítico (CaO: 28\%, MgO: 20\% e PRNT: 95\%) em todo o solo para elevar a saturação por bases a 70\%. Após a calagem, o solo foi mantido em sacos de plástico vedados por 30 dias com o teor de água mantido próximo à capacidade de campo para favorecer a reação do corretivo.

Em seguida, o solo foi secado ao ar novamente e adubado com $150 \mathrm{mg} \mathrm{dm}^{-3}$ de $\mathrm{P}$ (superfosfato simples) e $100 \mathrm{mg} \mathrm{dm}^{-3}$ de $\mathrm{K}$ (cloreto de potássio). Foram ainda aplicados 2,0 $\mathrm{mg} \mathrm{dm}^{-3} \mathrm{de} \mathrm{Mn}, 6,0 \mathrm{mg}$ $\mathrm{dm}^{-3}$ de $\mathrm{Zn}, 1,5 \mathrm{mg} \mathrm{dm}^{-3}$ de $\mathrm{Cu}, 2 \mathrm{mg} \mathrm{dm}{ }^{3}$ de B e 1 $\mathrm{mg} \mathrm{dm}{ }^{-3}$ de Mo, nas fontes $\mathrm{MnSO}_{4}, \mathrm{ZnSO}_{4}, \mathrm{CuSO}_{4}$, $\mathrm{H}_{3} \mathrm{BO}_{3}$ e $\left(\mathrm{NH}_{4}\right)_{2} \mathrm{MoO}_{4}$, respectivamente, via água de irrigação durante os 10 primeiros dias após a emergência das plântulas (DAE).

Foram utilizados vasos de $18 \mathrm{dm}^{3}$, cujo solo foi irrigado diariamente de maneira controlada para repor a água evapotranspirada, mantendo-se o nível de umidade próximo à capacidade de campo. As sementes de milho foram adquiridas a partir de lotes comerciais, em que havia tratamento prévio com fungicida (Thiram) na dose de 1,44 $\mathrm{g}$ de ingrediente ativo $\mathrm{kg}^{-1}$ de sementes.

As sementes foram inoculadas cerca de 2 horas antes da semeadura, de acordo com procedimentos de Mendonça, Urquiaga e Reis (2006). Foi utilizado um inoculante turfoso fornecido pela Embrapa
Agrobiologia (Seropédica, RJ), contendo a estirpe Herbaspirillum seropedicae (ZAE 94), com concentração de $1 \times 10^{8}$ células $\mathrm{g}^{-1}$, considerandose a dose de $25 \mathrm{~g}$ do inoculante $\mathrm{kg}^{-1}$ de sementes. Foram colocadas cinco sementes por vaso, e aos 5 DAE fez-se um desbaste deixando-se duas plantas por vaso.

Utilizou-se o delineamento experimental em blocos completos ao acaso, no esquema fatorial composto por 35 genótipos com ausência e presença de inoculação e quatro repetições, totalizandose 280 parcelas. Foram utilizados os seguintes genótipos: híbridos simples BRS 1030 (Embrapa), BRS 1031 (Embrapa), BRS 1035 (Embrapa), BRS 1010 (Embrapa), BRS 1001 (Embrapa); DKB 390 (Dekalb), DKB 789 (Dekalb), DAS 2B 587 (Dow Agrosciense), DAS 2B 710 (Dow Agrosciense), Somma (Syngenta), AG 8060 (Agroceres), AG 8088 (Agroceres), IAC 8333 (IAC), $30 \mathrm{~K} 73$ (Pioneer), 30 F 35 (Pioneer), 30 F 80 (Pioneer); híbridos duplos BRS 2020 (Embrapa), CD 308 (Coodetec), AGN 22 (Agromen), AGN 25 A 23 (Agromem), XB 8010 (Semeali), Tractor (Syngenta); híbridos triplos AG 5020 (Agroceres), AG 7010 (Agroceres), DKB 747 (Dekalb), DKB 979 (Dekalb), DKB 455 (Dekalb), DAS 2B 688 (Dow AgroScience), Master (Syngenta), Pioneer 30 F 87 (Pioneer); variedades AL Bandeirantes (Cati), AL Ipiranga (Cati), AL 34 (Cati), AL Piratininga (Cati) e AL Alvorada (Cati).

Aos 55 dias após a emergência fez-se o corte da parte aérea das plantas rente à superfície do solo, e a matéria vegetal foi submetida à secagem em estufa de aeração forçada a $60{ }^{\circ} \mathrm{C}$ até atingir massa constante. Após a quantificação da fitomassa seca da parte aérea, fez-se a determinação do teor e acúmulo de N da parte aérea das plantas (MALAVOLTA; VITTI; OLIVEIRA, 1997).

Os resultados foram submetidos à análise de variância, e quando houve diferença significativa entre tratamentos a $5 \%$ de probabilidade pelo teste F, foi aplicado o teste de Skott-Knott para comparar as médias dos tratamentos, também a $5 \%$ de probabilidade. 


\section{Resultados e Discussão}

Para a produção de matéria seca (MS) da parte aérea das plantas, houve interação significativa entre genótipos de milho e inoculação das sementes com Herbaspirillum seropedicae (ZAE 94) (Tabela 1). Parte das cultivares respondeu positivamente ao inoculante e parte negativamente, ou seja, houve incremento da MS para os híbridos simples BRS 1030, DKB 390 e Somma, e para os híbridos triplos DKB 747 e DKB 455. Por outro lado, a inoculação com bactérias diazotróficas prejudicou

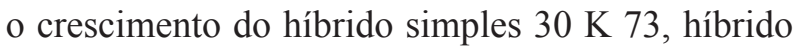
duplo Tractor, híbrido triplo Master e variedade AL Ipiranga (Tabela 1).

Relatos reforçam que são comuns respostas contraditórias de inoculação com bactérias diazotróficas endofíticas em culturas gramíneas, o que tem justificado investimentos para aprimorar tal tecnologia (SALA et al., 2007). Corrobora-se também que mesmo em ambientes controlados, como em casa de vegetação, têm sido frequentes respostas discrepantes de associação de bactérias diazotróficas e cultivares de milho, o que, provavelmente, tem limitado a consolidação de inoculantes comerciais (DOBBELAERE et al., 2002).

No trabalho de Sala et al. (2007), para um dos dois genótipos de arroz testados, sem adição de $\mathrm{N}$-fertilizante, as plantas que não receberam inoculação com bactérias diazotróficas apresentaram maior MS e $\mathrm{N}$ acumulado do que nos tratamentos com inoculação. Os autores argumentam que já foi observado em outros trabalhos que na ausência de adubo nitrogenado a inoculação pode reduzir a MS da parte aérea das plantas. Esse efeito negativo encontrado, também pode ser em razão de um aumento do sistema radicular, em detrimento do desenvolvimento aéreo. Uma das explicações para isso é que um dos benefícios proporcionados pelas bactérias diazotróficas em culturas gramíneas é a sua capacidade de produzir fito-hormônios (DOBBELAERE et al., 2001, 2002; MENDONÇA; URQUIAGA; REIS, 2006; SALA et al., 2007).
No estudo de Mendonça, Urquiaga e Reis (2006), foram avaliados os híbridos de milho BR 201, HS 20x22, BR 205 e Dekalb 644, e as variedades Sintético Elite, CMS 08, Sol da Manhã NF, Nitrodente e Catetão, e constatou-se que, apesar das bactérias diazotróficas terem colonizado raízes, colmos e folhas dos nove genótipos estudados, não foi observada contribuição da fixação biológica de N (FBN). Estudos sobre inoculação com bactérias diazotróficas em gramíneas, entre as quais o milho, têm demonstrado que, recorrentemente, o efeito positivo está mais associado à produção de fitohormônios do que à FBN (DOBBELAERE et al., 2001; MENDONÇA; URQUIAGA; REIS, 2006).

No presente trabalho, as cultivares que se destacaram na produção de MS, quando submetidas à inoculação, foram a DKB 390 e Somma (híbridos simples), CD 308 e AGN 25A23 (híbridos duplos) e DKB 455 e 30 F 87 (híbridos triplos).

Os híbridos triplos e simples apresentam maior uniformidade morfofisiológica entre os indivíduos de suas populações, sendo assim, em geral têm maior potencial produtivo quando as condições de ambiente são otimizadas. Por outro lado, os híbridos duplos e variedades apresentam menor uniformidade morfofisiológica entre os indivíduos em razão da maior diversidade genética, portanto, em geral têm maior estabilidade perante adversidades bióticas e abióticas (SAWAZAKI; PATERNIANI, 2004; PACHECO et al., 2006; CRUZ; PEREIRA FILHO, 2006).

Diante do exposto, é possível que em uma população com maior variabilidade genética haja menor especificidade na interação planta-bactéria, e isso pode ter resultado em ausência de resposta de produção de MS para as variedades e híbridos duplos no presente trabalho (Tabela 1). Sala et al. (2005) avaliaram a interação entre genótipos de trigo e bactérias diazotróficas endofíticas, e constataram que poucos isolados testados propiciaram benefícios ao trigo, e concluíram que um dos pontos cruciais para o sucesso no uso de organismos diazotróficos é a elucidação da especificidade genética na interação planta-bactéria. 
Tabela 1. Massa da matéria seca da parte aérea de 35 genótipos de milho aos 55 dias após a emergência, em função da inoculação das sementes com a estirpe Herbaspirillum seropedicae (ZAE 94).

\begin{tabular}{|c|c|c|c|c|}
\hline \multirow{2}{*}{$\begin{array}{l}\text { Grupo de } \\
\text { cruzamento }\end{array}$} & \multirow{2}{*}{ Cultivar } & \multicolumn{2}{|c|}{ Inoculação } & \multirow[t]{2}{*}{ Média } \\
\hline & & Ausência & Presença & \\
\hline & & ------------- & ---- g vaso ${ }^{-1}-----$ & ----------- \\
\hline \multirow[t]{16}{*}{ Híbrido simples } & BRS 1030 (Embrapa) & $33,31 \mathrm{Bd}$ & $38,44 \mathrm{~A} \mathrm{~b}$ & 35,87 \\
\hline & BRS 1031 (Embrapa) & $34,61 \mathrm{~A} \mathrm{c}$ & $36,51 \mathrm{~A} \mathrm{c}$ & 35,56 \\
\hline & BRS 1035 (Embrapa) & $35,01 \mathrm{~A} \mathrm{c}$ & $32,88 \mathrm{~A} \mathrm{~d}$ & 33,94 \\
\hline & BRS 1010 (Embrapa) & $34,28 \mathrm{~A} \mathrm{c}$ & $35,70 \mathrm{~A} \mathrm{c}$ & 34,99 \\
\hline & BRS 1001 (Embrapa) & $36,63 \mathrm{Ab}$ & $35,17 \mathrm{~A} \mathrm{c}$ & 35,90 \\
\hline & DKB 390 (Dekalb) & $34,49 \mathrm{~B} \mathrm{c}$ & $42,52 \mathrm{~A} \mathrm{a}$ & 38,50 \\
\hline & DKB 789 (Dekalb) & $35,38 \mathrm{~A} \mathrm{c}$ & $33,35 \mathrm{~A} \mathrm{~d}$ & 34,36 \\
\hline & DAS 2B587 (Dow Agro) & $37,13 \mathrm{~A} \mathrm{~b}$ & $35,86 \mathrm{~A} \mathrm{c}$ & 36,50 \\
\hline & DAS 2B710 (Dow Agro) & $35,35 \mathrm{~A} \mathrm{c}$ & $32,19 \mathrm{~A} \mathrm{~d}$ & 33,77 \\
\hline & Somma (Syngenta) & $38,01 \mathrm{~B} \mathrm{~b}$ & $42,83 \mathrm{~A} \mathrm{a}$ & 40,42 \\
\hline & AG 8060 (Agroceres) & $38,22 \mathrm{~A} \mathrm{~b}$ & $37,22 \mathrm{~A} \mathrm{~b}$ & 37,72 \\
\hline & AG 8088 (Agroceres) & $41,44 \mathrm{~A} \mathrm{a}$ & $39,04 \mathrm{~A} \mathrm{~b}$ & 40,24 \\
\hline & IAC 8333 (IAC) & $34,84 \mathrm{~A} \mathrm{c}$ & $33,84 \mathrm{Ad}$ & 34,34 \\
\hline & 30 K 73 (Pioneer) & $37,88 \mathrm{~A} \mathrm{~b}$ & $32,96 \mathrm{~B} \mathrm{~d}$ & 35,42 \\
\hline & 30 F 35 (Pioneer) & $36,77 \mathrm{~A} \mathrm{~b}$ & $39,47 \mathrm{~A} \mathrm{~b}$ & 38,12 \\
\hline & 30 F 80 (Pioneer) & $32,31 \mathrm{Ad}$ & $33,97 \mathrm{Ad}$ & 33,14 \\
\hline \multirow[t]{6}{*}{ Híbrido duplo } & BRS 2020 (Embrapa) & $39,88 \mathrm{~A} \mathrm{~b}$ & $37,52 \mathrm{~A} \mathrm{~b}$ & 38,70 \\
\hline & CD 308 (Codetec) & $40,26 \mathrm{~A} \mathrm{a}$ & $40,98 \mathrm{~A} \mathrm{a}$ & 40,62 \\
\hline & AGN 22 (Agromen) & $34,99 \mathrm{~A} \mathrm{c}$ & $37,69 \mathrm{~A} \mathrm{~b}$ & 36,34 \\
\hline & AGN 25A23 (Agromen) & $37,65 \mathrm{~A} \mathrm{~b}$ & $40,53 \mathrm{~A} \mathrm{a}$ & 39,09 \\
\hline & XB 8010 (Semeali) & $40,47 \mathrm{~A} \mathrm{a}$ & $37,66 \mathrm{~A} \mathrm{~b}$ & 39,06 \\
\hline & Tractor (Syngenta) & $38,73 \mathrm{~A} \mathrm{~b}$ & $34,76 \mathrm{~B} \mathrm{c}$ & 36,75 \\
\hline \multirow[t]{8}{*}{ Híbrido triplo } & AG 5020 (Agroceres) & $33,47 \mathrm{~A} \mathrm{c}$ & $34,68 \mathrm{~A} \mathrm{c}$ & 34,07 \\
\hline & AG 7010 (Agroceres) & $39,38 \mathrm{~A} \mathrm{~b}$ & $39,44 \mathrm{~A} \mathrm{~b}$ & 39,31 \\
\hline & DKB 747 (Dekalb) & $32,21 \mathrm{~B} \mathrm{~d}$ & $37,22 \mathrm{~A} \mathrm{~b}$ & 34,71 \\
\hline & DKB 979 (Dekalb) & $28,42 \mathrm{Ad}$ & $31,34 \mathrm{Ad}$ & 29,88 \\
\hline & DKB 455 (Dekalb) & $35,34 \mathrm{~B} \mathrm{c}$ & $41,65 \mathrm{~A} \mathrm{a}$ & 38,49 \\
\hline & DAS 2B 688 (Dow Agro) & $32,45 \mathrm{Ad}$ & $31,55 \mathrm{Ad}$ & 32,00 \\
\hline & Master (Syngenta) & $40,99 \mathrm{~A} \mathrm{a}$ & $37,01 \mathrm{~B} \mathrm{~b}$ & 39,01 \\
\hline & 30 F 87 (Pioneer) & $43,14 \mathrm{~A} \mathrm{a}$ & $40,82 \mathrm{~A} \mathrm{a}$ & 41,98 \\
\hline \multirow[t]{5}{*}{ Variedade } & AL Bandeirante (Cati) & $34,59 \mathrm{~A} \mathrm{~d}$ & $36,36 \mathrm{Ac}$ & 35,47 \\
\hline & AL Ipiranga (Cati) & $35,22 \mathrm{~A} \mathrm{c}$ & $30,33 \mathrm{~B} \mathrm{~d}$ & 32,77 \\
\hline & AL 34 (Cati) & $31,60 \mathrm{Ad}$ & $34,88 \mathrm{~A} \mathrm{c}$ & 33,24 \\
\hline & AL Piratininga (Cati) & $34,56 \mathrm{~A} \mathrm{c}$ & $33,28 \mathrm{Ad}$ & 33,92 \\
\hline & AL Alvorada (Cati) & $36,19 \mathrm{~A} \mathrm{c}$ & $36,23 \mathrm{~A} \mathrm{c}$ & 36,21 \\
\hline Média & & $36,09 \mathrm{X} x$ & $36,45 \mathrm{Xx}$ & \\
\hline \multirow[b]{2}{*}{ Causa da variação } & \multirow[b]{2}{*}{ F calculado } & \multicolumn{3}{|c|}{ Resposta positiva à inoculação } \\
\hline & & Tipo de cruzamento & $\begin{array}{c}\text { Dentro do grupo } \\
(\%)\end{array}$ & $\begin{array}{c}\text { Em relação ao } \\
\text { total }(\%)\end{array}$ \\
\hline Cultivar & $8,40 * *$ & Híbrido simples & 18,75 & 8,57 \\
\hline Inoculação & 1,20 ns* $^{*}$ & Híbrido triplo & 25,00 & 5,71 \\
\hline Cultivar x Inoculação & $2,93 * *$ & Híbrido duplo & 00,00 & 0,00 \\
\hline CV $(\%)$ & $8,54 * *$ & Variedade & 00,00 & 0,00 \\
\hline
\end{tabular}

Médias seguidas pelas mesmas letras, maiúsculas nas linhas e minúsculas nas colunas, não diferem entre si pelo teste de SkottKnott a 5\% de probabilidade. * e ** são significativos a 5\% e 1\% de probabilidade, respectivamente. ns: não significativo.

Fonte: Elaboração dos autores. 
Para o teor de $\mathrm{N}$ da parte aérea das plantas de seus teores de $\mathrm{N}$ da parte aérea das plantas milho, também houve interação significativa entre incrementados em resposta à inoculação das genótipos e inoculação com bactérias diazotróficas. sementes com Herbaspirillum seropedicae (ZAE Os híbridos simples BRS 1010 e DAS 2B587, 94). Em contrapartida, os híbridos simples AG 8060 híbrido duplo AGN 22, híbrido triplo Master e e 30 K 73, híbrido triplo DKB 979 e variedade AL variedades AL Ipiranga e AL Piratininga tiveram 34 sofreram redução nos teores de N (Tabela 2).

Tabela 2. Teor de $\mathrm{N}$ da parte aérea das plantas de 35 genótipos de milho aos 55 dias após a emergência, em função da inoculação das sementes com a estirpe Herbaspirillum seropedicae (ZAE 94).

\begin{tabular}{|c|c|c|c|c|}
\hline \multirow{2}{*}{ Grupo de cruzamento } & \multirow{2}{*}{ Cultivar } & \multicolumn{2}{|c|}{ Inoculação } & \multirow[t]{2}{*}{ Média } \\
\hline & & Ausência & Presença & \\
\hline & & ------------- & $\mathrm{g} \mathrm{kg}^{-1}----$ & $\begin{array}{l}------ \\
-1\end{array}$ \\
\hline \multirow[t]{16}{*}{ Híbrido simples } & BRS 1030 (Embrapa) & $14,40 \mathrm{~A} \mathrm{c}$ & $13,80 \mathrm{~A} \mathrm{c}$ & 14,10 \\
\hline & BRS 1031 (Embrapa) & $16,90 \mathrm{~A} \mathrm{c}$ & $16,02 \mathrm{~A} \mathrm{c}$ & 16,48 \\
\hline & BRS 1035 (Embrapa) & $18,30 \mathrm{Ac}$ & $19,70 \mathrm{~A} \mathrm{~b}$ & 19,00 \\
\hline & BRS 1010 (Embrapa) & $15,97 \mathrm{~B} \mathrm{c}$ & $19,77 \mathrm{~A} \mathrm{~b}$ & 17,87 \\
\hline & BRS 1001 (Embrapa) & $17,85 \mathrm{Ac}$ & $19,57 \mathrm{~A} \mathrm{~b}$ & 18,71 \\
\hline & DKB 390 (Dekalb) & 17,93 a c & $16,50 \mathrm{~A} \mathrm{c}$ & 17,22 \\
\hline & DKB 789 (Dekalb) & $17,20 \mathrm{Ac}$ & $18,87 \mathrm{~A} \mathrm{~b}$ & 18,03 \\
\hline & DAS 2B587 (Dow Agro) & $17,38 \mathrm{~B} \mathrm{c}$ & $23,10 \mathrm{~A} \mathrm{a}$ & 20,23 \\
\hline & DAS 2B710 (Dow Agro) & $17,00 \mathrm{Ac}$ & $18,40 \mathrm{~A} \mathrm{c}$ & 17,70 \\
\hline & Somma (Syngenta) & $16,23 \mathrm{Ac}$ & $18,09 \mathrm{~A} \mathrm{c}$ & 17,16 \\
\hline & AG 8060 (Agroceres) & $18,57 \mathrm{Ac}$ & $14,93 \mathrm{~B} \mathrm{c}$ & 16,75 \\
\hline & AG 8088 (Agroceres) & $16,35 \mathrm{Ac}$ & $16,58 \mathrm{Ac}$ & 16,49 \\
\hline & IAC 8333 (IAC) & $16,43 \mathrm{~A} \mathrm{c}$ & $16,88 \mathrm{~A} \mathrm{c}$ & 16,66 \\
\hline & 30 K 73 (Pioneer) & $25,20 \mathrm{~A} \mathrm{a}$ & $16,37 \mathrm{~B} \mathrm{c}$ & 20,78 \\
\hline & 30 F 35 (Pioneer) & $14,13 \mathrm{~A} \mathrm{c}$ & $14,76 \mathrm{~A} \mathrm{c}$ & 14,45 \\
\hline & 30 F 80 (Pioneer) & $19,70 \mathrm{Ab}$ & $17,17 \mathrm{~A} \mathrm{c}$ & 18,43 \\
\hline \multirow[t]{6}{*}{ Híbrido duplo } & BRS 2020 (Embrapa) & $15,03 \mathrm{Ac}$ & $16,33 \mathrm{Ac}$ & 15,68 \\
\hline & CD 308 (Codetec) & $15,30 \mathrm{Ac}$ & $16,47 \mathrm{~A} \mathrm{c}$ & 15,88 \\
\hline & AGN 22 (Agromen) & $17,73 \mathrm{~B} \mathrm{c}$ & $21,43 \mathrm{~A} \mathrm{a}$ & 19,58 \\
\hline & AGN 25A23 (Agromen) & $16,40 \mathrm{Ac}$ & $16,60 \mathrm{~A} \mathrm{c}$ & 16,50 \\
\hline & XB 8010 (Semeali) & $17,27 \mathrm{Ac}$ & $17,53 \mathrm{Ac}$ & 17,40 \\
\hline & Tractor (Syngenta) & $16,45 \mathrm{Ac}$ & $17,83 \mathrm{~A} \mathrm{c}$ & 17,13 \\
\hline \multirow[t]{8}{*}{ Híbrido triplo } & AG 5020 (Agroceres) & $21,83 \mathrm{~A} \mathrm{~b}$ & $20,43 \mathrm{~A} \mathrm{~b}$ & 21,13 \\
\hline & AG 7010 (Agroceres) & $17,33 \mathrm{Ac}$ & $17,07 \mathrm{~A} \mathrm{c}$ & 17,20 \\
\hline & DKB 747 (Dekalb) & $17,00 \mathrm{Ac}$ & $17,27 \mathrm{Ac}$ & 17,14 \\
\hline & DKB 979 (Dekalb) & $23,48 \mathrm{~A} \mathrm{a}$ & $17,60 \mathrm{~B} \mathrm{c}$ & 20,54 \\
\hline & DKB 455 (Dekalb) & $15,83 \mathrm{~A} \mathrm{c}$ & $17,08 \mathrm{~A} \mathrm{c}$ & 16,46 \\
\hline & DAS 2B 688 (Dow Agro) & $19,53 \mathrm{Ab}$ & $18,87 \mathrm{~A} \mathrm{~b}$ & 19,20 \\
\hline & Master (Syngenta) & $16,95 \mathrm{~B} \mathrm{c}$ & $24,43 \mathrm{~A} \mathrm{a}$ & 20,67 \\
\hline & 30 F 87 (Pioneer) & $16,80 \mathrm{Ac}$ & $17,86 \mathrm{~A} \mathrm{c}$ & 17,33 \\
\hline \multirow[t]{5}{*}{ Variedade } & AL Bandeirante (Cati) & $20,17 \mathrm{~A} \mathrm{~b}$ & $19,40 \mathrm{~A} \mathrm{~b}$ & 19,78 \\
\hline & AL Ipiranga (Cati) & $20,00 \mathrm{~B} \mathrm{~b}$ & $23,07 \mathrm{~A} \mathrm{a}$ & 21,53 \\
\hline & AL 34 (Cati) & $22,87 \mathrm{~A} \mathrm{a}$ & $16,23 \mathrm{~B} \mathrm{c}$ & 19,55 \\
\hline & AL Piratininga (Cati) & $18,40 \mathrm{~B} \mathrm{c}$ & $21,67 \mathrm{~A} \mathrm{a}$ & 20,03 \\
\hline & AL Alvorada (Cati) & $21,17 \mathrm{~A} \mathrm{~b}$ & $19,40 \mathrm{~A} \mathrm{~b}$ & 20,28 \\
\hline
\end{tabular}


continuação

\begin{tabular}{lcccc}
\hline Média & & \multicolumn{2}{c}{$17,97 \mathrm{X} x$} & \multicolumn{2}{c}{$18,20 \mathrm{X}$ x } \\
\hline \multirow{3}{*}{ Causa da variação } & \multirow{2}{*}{ F calculado } & $\begin{array}{l}\text { Grupo de } \\
\text { cruzamento }\end{array}$ & $\begin{array}{l}\text { Dentro do } \\
\text { grupo }(\%)\end{array}$ & $\begin{array}{c}\text { Em relação ao total } \\
(\%)\end{array}$ \\
\hline Cultivar & $5,11^{* *}$ & Híbrido simples & 12,50 & 5,71 \\
Inoculação & $0,65^{\mathrm{ns}}$ & Híbrido triplo & 12,50 & 2,86 \\
Cultivar x Inoculação & $3,54^{*}$ & Híbrido duplo & 16,67 & 2,86 \\
\hline CV $(\%)$ & 13,20 & Variedade & 40,00 & 5,71 \\
\hline
\end{tabular}

Médias seguidas pelas mesmas letras, maiúsculas nas linhas e minúsculas nas colunas, não diferem entre si pelo teste de SkottKnott a $5 \%$ de probabilidade. * e ** são significativos a $5 \%$ e $1 \%$ de probabilidade, respectivamente. ns: não significativo.

Fonte: Elaboração dos autores.

As cultivares que se destacaram no teor de $\mathrm{N}$ da parte aérea, quando submetidas à inoculação, foram a DAS 2B587 (híbrido simples), AGN 22 (híbrido duplo), Master (híbrido triplo), AL Ipiranga e AL Piratininga (variedades). Analisandose o desempenho das variedades, observa-se que ao contrário do que foi observado para a produção de MS das plantas de milho (Tabela 1), duas variedades foram favorecidas no teor de $\mathrm{N}$ quando inoculadas com a estirpe $H$. seropedicae (ZAE 94).

$\mathrm{Na}$ avaliação do acúmulo de $\mathrm{N}$ na parte aérea das plantas de milho, foram encontradas respostas positivas à inoculação em 17,1\% dos genótipos testados (Tabela 3). Apresentaram incrementos significativos de $\mathrm{N}$ acumulado os híbridos simples BRS 1010, DAS 2B587 e Somma, o híbrido duplo AGN 22 e os híbridos triplos DKB 455 e Master. Por outro lado, a inoculação com a estirpe $H$. seropedicae (ZAE 94) foi prejudicial ao acúmulo de N para os híbridos simples AG 8060, 30 K 73 e para a variedade AL 34 (Tabela 3).

Quando houve inoculação das sementes, os destaques de $\mathrm{N}$ acumulado foram para os híbridos simples DAS 2B587 e Somma, para o híbrido duplo AGN 22 e para o híbrido triplo Master (Tabela 3). Por outro lado, da mesma forma que ocorreu para a produção de MS (Tabela 1), não houve incremento de $\mathrm{N}$ acumulado para nenhuma das variedades estudadas. Portanto, os resultados positivos de resposta à inoculação concentraram-se nos genótipos híbridos de milho, indicando tendência de maior afinidade desse grupo com o microssimbionte. No trabalho de Ferreira, Baldani e Baldani (2010) verificaram-se diferenças expressivas de acúmulo de $\mathrm{N}$ entre cultivares de arroz quando submetidas à inoculação com bactérias diazotróficas, e concluiuse que as discrepâncias de repostas podem estar associadas a estirpe utilizada, ou seja, corroborase que é fundamental elucidar a interação estirpecultivar.

De acordo com Paterniani e Campos (1999), os híbridos simples e triplos possuem menor amplitude genética em comparação aos híbridos duplos e variedades de milho, e a estirpe fixadora de $\mathrm{N}$ utilizada no presente estudo apresentou maior potencial de afinidade com os genótipos de menor grau de cruzamento, para os atributos produção de MS e $\mathrm{N}$ acumulado na parte aérea (Tabelas 1 e 3). Porém, no caso específico do teor de $\mathrm{N}$ das plantas, parte expressiva das variedades respondeu positivamente à inoculação.

Em termos gerais, observa-se nas tabelas 1, 2 e 3 que menos de $20 \%$ das 35 cultivares de milho avaliadas apresentaram respostas positivas à inoculação das sementes com a estirpe $H$. seropedicae (ZAE 94). Portanto, evidencia-se como primordial estabelecer critérios para distinguir cultivares de milho em termos de afinidade com estirpes de microrganismos, tanto do ponto de vista de produção de fito-hormônios como em termos de FBN. 
Tabela 3. Acúmulo de $\mathrm{N}$ na fitomassa da parte aérea de 35 genótipos de milho aos 55 dias após a emergência, em função da inoculação das sementes com a estirpe Herbaspirillum seropedicae (ZAE 94).

\begin{tabular}{|c|c|c|c|c|}
\hline \multirow{2}{*}{ Grupo de cruzamento } & \multirow{2}{*}{ Cultivar } & \multicolumn{2}{|c|}{ Inoculação } & \multirow[t]{2}{*}{ Média } \\
\hline & & Ausência & Presença & \\
\hline & & ------- & - g vaso $^{-1}$ & |-------------- \\
\hline \multirow[t]{16}{*}{ Híbrido simples } & BRS 1030 (Embrapa) & $0,47 \mathrm{Ac}$ & $0,53 \mathrm{Ac}$ & 0,50 \\
\hline & BRS 1031 (Embrapa) & $0,59 \mathrm{Ac}$ & $0,58 \mathrm{Ac}$ & 0,59 \\
\hline & BRS 1035 (Embrapa) & $0,64 \mathrm{Ac}$ & $0,65 \mathrm{~A} \mathrm{c}$ & 0,64 \\
\hline & BRS 1010 (Embrapa) & $0,55 \mathrm{~B} \mathrm{c}$ & $0,73 \mathrm{~A} \mathrm{~b}$ & 0,64 \\
\hline & BRS 1001 (Embrapa) & $0,63 \mathrm{~A} \mathrm{c}$ & $0,69 \mathrm{Ab}$ & 0,66 \\
\hline & DKB 390 (Dekalb) & $0,62 \mathrm{~A} \mathrm{c}$ & $0,70 \mathrm{~A} \mathrm{~b}$ & 0,66 \\
\hline & DKB 789 (Dekalb) & $0,61 \mathrm{Ac}$ & $0,63 \mathrm{Ac}$ & 0,62 \\
\hline & DAS 2B587 (Dow Agro) & $0,64 \mathrm{~B} \mathrm{c}$ & $0,84 \mathrm{~A} \mathrm{a}$ & 0,74 \\
\hline & DAS 2B710 (Dow Agro) & $0,60 \mathrm{~A} \mathrm{c}$ & $0,59 \mathrm{~A} \mathrm{c}$ & 0,60 \\
\hline & Somma (Syngenta) & $0,59 \mathrm{~B} \mathrm{c}$ & $0,78 \mathrm{~A} \mathrm{a}$ & 0,68 \\
\hline & AG 8060 (Agroceres) & $0,71 \mathrm{~A} \mathrm{~b}$ & $0,55 \mathrm{~B} \mathrm{c}$ & 0,63 \\
\hline & AG 8088 (Agroceres) & $0,68 \mathrm{~A} \mathrm{~b}$ & $0,64 \mathrm{Ac}$ & 0,66 \\
\hline & IAC 8333 (IAC) & $0,58 \mathrm{~A} \mathrm{c}$ & $0,57 \mathrm{Ac}$ & 0,57 \\
\hline & 30 K 73 (Pioneer) & $1,20 \mathrm{~A} \mathrm{a}$ & $0,54 \mathrm{~B} \mathrm{c}$ & 0,87 \\
\hline & 30 F 35 (Pioneer) & $0,52 \mathrm{~A} \mathrm{c}$ & $0,58 \mathrm{~A} \mathrm{c}$ & 0,55 \\
\hline & 30 F 80 (Pioneer) & $0,63 \mathrm{Ac}$ & $0,59 \mathrm{Ac}$ & 0,61 \\
\hline \multirow[t]{6}{*}{ Híbrido duplo } & BRS 2020 (Embrapa) & $0,60 \mathrm{Ac}$ & $0,61 \mathrm{Ac}$ & 0,61 \\
\hline & CD 308 (Codetec) & $0,62 \mathrm{~A} \mathrm{c}$ & $0,68 \mathrm{Ab}$ & 0,65 \\
\hline & AGN 22 (Agromen) & $0,62 \mathrm{~B} \mathrm{c}$ & $0,82 \mathrm{~A} \mathrm{a}$ & 0,72 \\
\hline & AGN 25A23 (Agromen) & $0,61 \mathrm{Ac}$ & $0,67 \mathrm{~A} \mathrm{~b}$ & 0,64 \\
\hline & XB 8010 (Semeali) & $0,70 \mathrm{~A} \mathrm{~b}$ & $0,65 \mathrm{Ac}$ & 0,68 \\
\hline & Tractor (Syngenta) & $0,64 \mathrm{~A} \mathrm{c}$ & $0,62 \mathrm{~A} \mathrm{c}$ & 0,63 \\
\hline \multirow[t]{8}{*}{ Híbrido triplo } & AG 5020 (Agroceres) & $0,73 \mathrm{~A} \mathrm{~b}$ & $0,71 \mathrm{Ab}$ & 0,72 \\
\hline & AG 7010 (Agroceres) & $0,68 \mathrm{~A} \mathrm{~b}$ & $0,67 \mathrm{~A} \mathrm{~b}$ & 0,68 \\
\hline & DKB 747 (Dekalb) & $0,55 \mathrm{Ac}$ & $0,64 \mathrm{Ac}$ & 0,59 \\
\hline & DKB 979 (Dekalb) & $0,67 \mathrm{~A} \mathrm{~b}$ & $0,55 \mathrm{~A} \mathrm{c}$ & 0,61 \\
\hline & DKB 455 (Dekalb) & $0,56 \mathrm{~B} \mathrm{c}$ & $0,72 \mathrm{~A} \mathrm{~b}$ & 0,64 \\
\hline & DAS 2B 688 (Dow Agro) & $0,64 \mathrm{~A} \mathrm{c}$ & $0,59 \mathrm{Ac}$ & 0,61 \\
\hline & Master (Syngenta) & $0,70 \mathrm{~B} \mathrm{~b}$ & $0,91 \mathrm{~A} \mathrm{a}$ & 0,80 \\
\hline & 30 F 87 (Pioneer) & $0,72 \mathrm{~A} \mathrm{~b}$ & $0,73 \mathrm{~A} \mathrm{~b}$ & 0,72 \\
\hline \multirow[t]{5}{*}{ Variedade } & AL Bandeirante (Cati) & $0,66 \mathrm{~A} \mathrm{c}$ & $0,70 \mathrm{~A} \mathrm{~b}$ & 0,68 \\
\hline & AL Ipiranga (Cati) & $0,71 \mathrm{~A} \mathrm{~b}$ & $0,70 \mathrm{~A} \mathrm{~b}$ & 0,70 \\
\hline & AL 34 (Cati) & $0,71 \mathrm{~A} \mathrm{~b}$ & $0,57 \mathrm{~B} \mathrm{c}$ & 0,64 \\
\hline & AL Piratininga (Cati) & $0,64 \mathrm{~A} \mathrm{c}$ & $0,72 \mathrm{~A} \mathrm{~b}$ & 0,68 \\
\hline & AL Alvorada (Cati) & $0,77 \mathrm{Ab}$ & $0,70 \mathrm{~A} \mathrm{~b}$ & 0,74 \\
\hline \multicolumn{2}{|l|}{ Média } & $0,65 \mathrm{Xx}$ & $0,66 \mathrm{Xx}$ & \\
\hline \multirow[b]{2}{*}{ Causa da variação } & & \multicolumn{3}{|c|}{ Resposta positiva à inoculação } \\
\hline & F calculado & $\begin{array}{l}\text { Grupo de } \\
\text { cruzamento }\end{array}$ & $\begin{array}{l}\text { Dentro do } \\
\text { grupo (\%) }\end{array}$ & $\begin{array}{c}\text { Em relação ao total } \\
(\%)\end{array}$ \\
\hline Cultivar & $04,04 *$ & Híbrido simples & 18,75 & 8,57 \\
\hline Inoculação & $00,93^{\mathrm{ns}}$ & Híbrido triplo & 25,00 & 5,71 \\
\hline Cultivar x Inoculação & $04,73 *$ & Híbrido duplo & 16,67 & 2,86 \\
\hline CV (\%) & $14,93 *$ & Variedade & 0,00 & 0,00 \\
\hline
\end{tabular}

Médias seguidas pelas mesmas letras, maiúsculas nas linhas e minúsculas nas colunas, não diferem entre si pelo teste de SkottKnott a $5 \%$ de probabilidade. * e ** são significativos a $5 \%$ e $1 \%$ de probabilidade, respectivamente. ns: não significativo.

Fonte: Elaboração dos autores. 
Segundo Malavolta, Vitti e Oliveira (1997), teores de $\mathrm{N}$ relativamente elevados são comuns em plantas que têm problemas de crescimento, e o inverso também é verdadeiro, ou seja, plantas com altas taxas de produção de MS em geral apresentam baixos teores de $\mathrm{N}$ nos tecidos, pois o nutriente é translocado para a formação de novas estruturas, caracterizando o chamado "efeito diluição". No presente trabalho, em termos relativos, os híbridos simples apresentaram maiores produções de MS do que as variedades, e por sua vez, as variedades apresentaram maiores teores de $\mathrm{N}$ na parte aérea das plantas (Tabelas 1 e 2). Sendo assim, além da compreensão das especificidades na interação planta-bactéria, é preciso considerar que determinados grupos de genótipos de milho podem responder mais a fito-hormônios produzidos por bactérias diazotróficas, e outros podem ser mais responsivos à $\mathrm{FBN}$, corroborando as argumentações de Dobbelaere et al. (2001) e Mendonça, Urquiaga e Reis (2006).

O germoplasma do milho é constituído por raças crioulas, populações adaptadas e materiais introduzidos, os quais são caracterizados como de ampla variabilidade genética (PATERNIANI; CAMPOS, 1999), e essa variabilidade é um dos principais fatores que podem interferir na eficiência de uso do N (MAJEROWICZ et al., 2002). As razões para a variabilidade de resposta à $\mathrm{FBN}$ em gramíneas ainda não foram completamente elucidadas, o que tem reforçado a tese de que a interação genótipobactéria-ambiente exerça papel decisivo sobre a eficiência do diazotrófico (GYANESHWAR et al., 2002).

Em trabalho com diferentes genótipos utilizandose a técnica do $\mathrm{N}_{15}$, Mendonça, Urquiaga e Reis (2006) relataram que todos os híbridos e variedades de milho não receberam significativa contribuição da FBN, mesmo quando as bactérias diazotróficas estavam presentes no interior das plantas de milho. Zilli et al. (2007) avaliando a mesma estirpe de $H$. seropedicae utilizada neste trabalho e observaram que em condições de campo o milho híbrido BRS
1010 respondeu significativamente à inoculação, o que não aconteceu com a variedade BRS 4157. Salienta-se que no presente estudo o genótipo BRS 1010 foi um dos poucos híbridos simples que respondeu a inoculação no tocante ao aumento do teor de N (Tabela 2).

De acordo com Sawazaki e Paterniani (2004), os milhos híbridos são produzidos para serem utilizados em sistemas de produção com elevado aporte tecnológico, que engloba grande adição de $\mathrm{N}$-fertilizante. Por outro lado, os híbridos são considerados de menor amplitude genética quando comparados às variedades (PATERNIANI; CAMPOS, 1999), e essa característica pode influenciar a interação com bactérias diazotróficas endofíticas.

Neste trabalho os genótipos híbridos de milho foram mais responsivos do que as variedades de milho, em termos de produção de MS e $\mathrm{N}$ acumulado na parte aérea das plantas (Tabelas 1 e 3). Essa constatação pode revelar também que as variedades de milho podem ter desenvolvido interações com diazotróficos nativos do solo, e a inoculação com a estirpe selecionada não foi suficiente para melhorar o desempenho de crescimento. Sobre a possibilidade da interação dos genótipos com diazotróficos nativos é importante salientar que, de acordo com Olivares et al. (1996), a sobrevivência de bactérias diazotróficas no solo na ausência de plantas é baixa.

As interações entre cultivares de milho e bactérias fixadoras de $\mathrm{N}$ e/ou promotoras de crescimento são dependentes de especificidades na interação entre genótipos da planta e estirpes dos microrganismos envolvidos (ALFOLDI; PINTER; FEIL, 1992; GARCIA DE SALOMONE; DÖBEREINER, 1996; MACHADO et al., 2001). $\mathrm{O}$ insucesso no crescimento e teor de $\mathrm{N}$ encontrado na maioria dos genótipos de milho submetidos à inoculação com Herbaspirillum seropedicae (ZAE 94) confirma a situação de baixa interação entre os simbiontes, pois menos de $20 \%$ dos genótipos avaliados foram responsivos à inoculação. Além disto, mesmo os genótipos de milho responsivos 
à inoculação, detectados neste estudo, não conseguiram atingir teores de $\mathrm{N}$ foliar adequados à cultura (MALAVOLTA.; VITTI; OLIVEIRA, 1997), revelando que pode haver necessidade de complementação de $\mathrm{N}$ mineral.

De acordo com Bashand e Levanony (1990), aumentos moderados, em torno de 10 a $20 \%$, atribuídos à presença de bactérias diazotróficas endofíticas na cultura do milho, seriam considerados comercialmente significativos na agricultura moderna. Os resultados encontrados reforçam também a necessidade de se ter maior integração dos programas de melhoramento de milho com a utilização de bactérias fixadores de $\mathrm{N}$ e/ou promotoras de crescimento, pois, foram encontrados respostas significativas para alguns genótipos.

\section{Conclusões}

1. Dos 35 genótipos comerciais de milho estudados, híbridos e variedades, apenas nove híbridos apresentam ganhos de crescimento ou acúmulo de $\mathrm{N}$ com a inoculação das sementes com a estirpe Herbaspirillum seropedicae (ZAE 94).

2. Há distinção de resposta entre cultivares de milho em termos de produção de biomassa e incremento de teor de $\mathrm{N}$ na parte aérea das plantas.

\section{Referências}

ALFOLDI, Z.; PINTER, L.; FEIL, B. Accumulation and partitioning of biomass and soluble carbohydrates in maize seedlings as affected by source of nitrogen, nitrogen concentration and cultivar. Journal of Plant Nutrition, Philadelphia, v. 15, n. 11, p. 2567-2583, 1992.

BASHAND, Y.; LEVANONY, H. Current status of Azospirillum inoculation technology: Azospirillum as a challenge for agriculture. Canadian Journal of Microbiology, Ottawa, v. 36, n. 3, p. 591-608, 1990.

BODDEY, R. M.; OLIVEIRA, O. C.; URQUIAGA, S.; REIS, V. M.; OLIVARES, F. L.; BALDANI, V. L. D. DÖBEREINER, J. Biological nitrogen fixation associated with sugarcane and rice: contributions and prospects for improvement. Plant Soil, The Hague, v. 174, n. 3, p. 195-209, 1995.
CARLONE, M. R.; RUSSEL, W. A. Response to plant densities and nitrogen levels for four maize cultivars from different eras of breeding. Crop Science, Madison, v. 27, n. 2, p. 465-470, 1987.

CRUZ, J. C.; PEREIRA FILHO, I. A. Cuidados na escolha da cultivar de milho. Sete Lagoas: Embrapa Milho e Sorgo, 2006. 6 p. (Embrapa Milho e Sorgo, Comunicado técnico, 133),

DOBBELAERE, S.; CROONENBORGHS, A.; THYS, A.; PTACEK, D.; OKON, Y.; VANDERLEYDEN, J. Effect of inoculation with wild type Azospirillum brasilense and $A$. irakense strains on development and nitrogen uptake of spring wheat and grain maize. Biology and Fertility of Soils, Germany, v. 36, n. 4, p. 284-297, 2002.

DOBBELAERE, S.; CROONENBORGHS, A.; THYS, A.; PTACEK, D.; VANDERLEYDEN, J.; DUTTO, P.; LABANDERAGONZALEZ, C.; CABALLEROMELLADO, J.; AGUIRRE, J.F.; KAPULNIK, Y.; BRENER, S.; BURDMAN, S.; KADOURI, D.; SARIG, S.; OKON, Y. Responses of agronomically important crops to inoculation with Azospirillum. Australian Journal of Plant Physiology, Sydney, v. 28, n. 9, p. 871879, 2001.

EMPRESA BRASILEIRA DE PESQUISA AGROPECUÁRIA - EMBRAPA. Centro Nacional de Pesquisa de Solos. Sistema brasileiro de classificação de solos. Rio de Janeiro, 2006. 306 p.

Centro Nacional de Pesquisa de Solos. Manual de métodos de análise de solo. 2. ed. Rio de Janeiro, 1997. $212 \mathrm{p}$.

FERREIRA, J. S.; BALDANI, J. I.; BALDANI, V. L. D. Seleção de inoculantes à base de turfa contendo bactérias diazotróficas em duas variedades de arroz. Acta Scientiarum, Maringá, v. 32, n. 1, p. 179-185, 2010.

GARCIA DE SALAMONE, I.; DOBEREINER, J. Maize genotype effects on the response to Azospirillum inoculation. Biology and Fertility of Soils, Germany, v. 21, n. 3, p. 193-196, 1996.

GYANESHWAR, P.; JAMES, E. K.; REDDY, P. M.; LADHA, J. Herbaspirillum colonization increases growth and nitrogen accumulation in aluminium-tolerant rice varieties. New Phytologist, New York, v. 154, n. 2, p. 131-145, 2002.

MACHADO, A. T.; SODEK, L.; DOBEREINER, J.; REIS, V. M. Efeito da adubação nitronenada e da inoculação com bactérias diazotróficas no comportamento bioquímico da cultivar de milho Nitroflint. Pesquisa Agropecuária Brasileira, Brasília, v. 33, n. 6, p. 961-970, 1998. 
MACHADO, A. T.; SODEK, L.; FERNANDES, M. S. N. Partioning, nitrate reductase and glutamine synthetase activities in two contrasting varietes of maize. Pesquisa Agropecuária Brasileira, Brasília, v. 36, n. 2, p. 249-256, 2001.

MAJEROWICZ, N.; MAJEROWICZ, N.; PEREIRA, J. M. S.; MEDICI, L. O.; BISON, O.; PEREIRA, M. B.; SANTOS JÚNIOR, U. M. Estudo da eficiência de uso do nitrogênio em variedades locais e melhoradas de milho. Revista Brasileira de Botânica, São Paulo, v. 25, n. 2, p. 129-136, 2002.

MALAVOLTA, E. A.; VITTI, G. C.; OLIVEIRA, S. A. Avaliação do estado nutricional das plantas: princípios e aplicações. Piracicaba: POTAFOS, 1997. 201 p.

MENDONÇA, M. M.; URQUIAGA, S. S.; REIS, V. M. Variabilidade genotípica de milho para acumulação de nitrogênio e contribuição da fixação biológica de nitrogênio. Pesquisa Agropecuária Brasileira, Brasília, v. 41, n. 11, p. 1681-1685, 2006.

OLIVARES, F. L.; BALDANI, V. L. D.; REIS, V. M.; BALDANI, J. I.; DOBEREINER, J. Ocurrence of the endophytic diazotrophs Herbaspirillum spp. In roots, stems and leaves of graminae. Biology and Fertility of Soils, Germany, v. 21, n. 2, p. 197-200, 1996.

PACHECO, C. A. P.; GUIMARÃES, P. E. de O.; GARCIA, J. C.; GAMA, E. E. G. E.; MEIRELLES, W. F. Avaliação do efeito econômico da substituição de variedades por híbridos, na Região Central do Brasil. Sete Lagoas: Embrapa Milho e Sorgo, 2006. 15 p. (Embrapa Milho e Sorgo, Documentos 57).

PATERNIANI, E.; CAMPOS, M. S. Melhoramento do milho. In: BORÉM, A. Melhoramento de espécies cultivares. Viçosa: UFV, 1999. p. 429-487.

RAIJ, B. van; ANDRADE, J. C.; CANTARELLA, H.; QUAGGIO, J. A. Análise química para avaliação da fertilidade de solos tropicais. Campinas: Instituto Agronômico, 2001. 284 p.
REIS, V. M.; BALDANI, V. L. D.; BALDANI, J. I.; DOBEREINER, J. Biological nitrogen fixation in gramineae and palm trees. Critical Review in Plant Science, London, v. 19, n. 3, p. 227-247, 2000.

RIGGS, P. J.; CHELIUS, M. K.; INIGUEZ, A. L.; KAEPPLER, S. M.; TRIPLETT, E. W. Enhanced maize productivity by inoculation with diazotrophic bacteria. Australian Journal of Plant Physiology, Sydney, v. 28, n. 9, p. 829-836, 2001.

ROESCH, L. F.; CAMARGO, F.; SELBACH, P.; SAES, P. L. Identificação de cultivares de milho eficientes na absorção de nitrogênio e na associação com bactérias diazotróficas. Ciência Rural, Santa Maria, v. 35, n. 4, p. 924-927, 2005.

SALA, V. M. R.; CARDOSO, E. J. B. N.; FREITAS, J. G. de; SILVEIRA, A. P. D. da. Resposta de genótipos de trigo à inoculação de bactérias diazotróficas em condições de campo. Pesquisa Agropecuária Brasileira, Brasília, v. 42, n. 6, p. 833-842, 2007.

SALA, V. M. R.; FREITAS, S. S.; DONZELI, V. P.; FREITAS, J. G.; GALLO, P. B.; SILVEIRA, A. P. D. Ocorrência e efeito de bactérias diazotróficas em genótipos de trigo. Revista Brasileira de Ciência do Solo, Viçosa, MG, v. 29, n. 4, p. 345-352, 2005.

SAWAZAKI, E.; PATERNIANI, M. E. A. Z. Evolução dos cultivares de milho no Brasil. In: GALVÃO, J. C. C.; MIRANDA, G. V. (Ed.). Tecnologias de produção do milho. Viçosa, MG: Universidade Federal de Viçosa, 2004. p. 55-84.

ZILLI, J. E.; MARSON, L. C.; REIS, V. M.; ALVES, G. M.; BALDANI, V. L. D.; CORDEIRO, A. C. C. Contribuição da Bactéria diazotrófica Herbaspirillum seropedicae para o rendimento de grãos de arroz e milho em Roraima. Boa Vista: Embrapa Roraima, 2007. 20 p. (Boletim de Pesquisa e Desenvolvimento/Embrapa Roraima, 6). 
